\title{
Francisco Sosa, el género biográfico y la teoría del grande hombre
}

\author{
José Ortiz Monasterio \\ INSTITUTO MORA
}

PRESENTACIÓN

$\mathrm{E}$ ste ensayo es una versión directa y modernizada, sólo en minucias de ortografía y puntuación, del estudio que sobre Francisco Sosa hiciera Vicente Riva Palacio en 1882 en el libro que tituló Los Ceros, galería de contemporáneos. ${ }^{1}$ La obra es de admirable fac-

\footnotetext{
1 Cero (seud, de Vicente Riva Palacio), Los Ceros, galeria de contemporáneos, por... Imprenta de F. Díaz de León, México, 1882. La cuestión de la paternidad de los "Ceros" fue resuelta por Clementina Díaz y de Ovando en su tesis doctoral: "La incógnita de algunos Ceros de Vicente Riva Palacio", UNAM, 1965. El asunto es que ciertos artículos firmados por "Cero" aparecieron en el periódico La República en los tres primeros meses de
}

\section{1}

tura por su fino humorismo, por la erudición rica y variada que despliega sin afectación y por los rasgos biográficos que ofrece de los escritores de aquella generación. El objeto principal de Riva Palacio fue rendir homenaje a sus contemporáneos mediante semblanzas en las que con rara habilidad hace alternar a los ingenios locales -Sierra, Prieto, Peón

1882 y del seudónimo tomaron su nombre para llamarse a su vez "Ceros". Tras el seudónimo se escondía originalmente Juan de Dios Peza, pero en la época era frecuente en la redacción de los periódicos que intervinieran varias plumas; asi, Riva Palacio comenzó a colaborar en los "Ceros" con Peza hasta que sucedió lo que cuenta don Vicente en alguna parte: "A un amigo yo llevé a casa de la que amaba, y tanto llegué a llevarlo que después él 


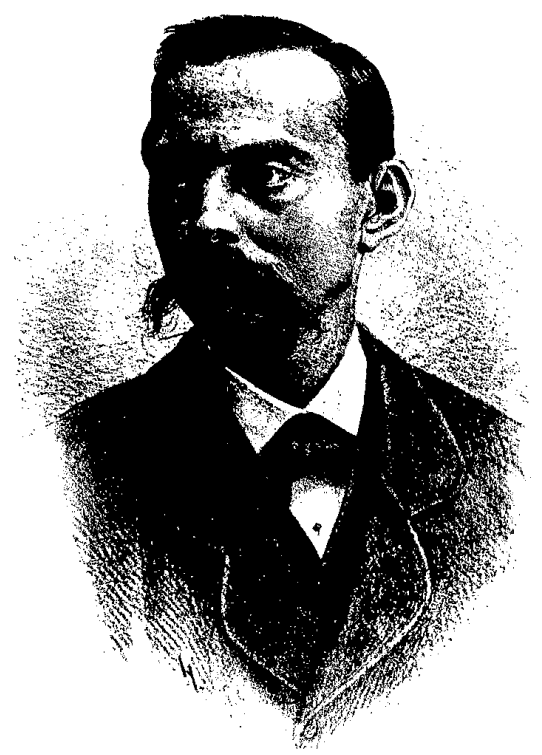

Contreras, Ipandro Acaico, Vigil, Aguilar y Marocho, Payno, entre otros- con los hombres ilustres de todos los tiempos,

me llevaba." Meses más tarde algunos de los "Ceros" publicados en el periódico se reunieron, con modificaciones importantes, en el libro mencionado al principio de esta nota y sobre el cual no hay duda que es obra exclusiva del magin rivapalatino. Algunos "Ceros" fueron reproducidos en forma aislada años después y tenemos noticia de que el señor Bruno Pagliai regaló a sus amigos en 1972 -por sugerencia de Andrés Henestrosa- una edición facsilmilar privada del libro completo, pero ésta no la hemos tenido en nuestras manos. En 1979 sugerimos a Promexa Editores la edición de esta obra y en efecto se publicó en una promoción de las que se adquieren en los supermercados, que paradójicamente se venden mucho pero sólo son accesibles al público por unas cuantas semanas. Por eso publicamos ahora el "Cero" cuyo título original era sencillamente "Francisco Sosa", tomado de las páginas 243 a 267 de la edición original de 1882 . Véase Vicente Riva Palacio, Cuentos delgeneral y Los Ceros, galería de contemporáneos, pról. de José Ortiz Monasterio, Promexa Editores, México, 1979 (Clásicos de la Literatura Mexicana). ganando así los mexicanos un lugar en la historia universal (y por ello nos presenta a Sosa acompañado de los grandes biógrafos de la antigüedad); pero a la vez don Vicente aprovecha el viaje, por así decirlo, para transmitir sus ideas sobre las materias más variadas. En este caso la inclinación de Sosa por la biografía le sirve de excusa para discutir la llamada teoría del gran o grande hombre y contrastarla con el positivismo de Herbert Spencer. Es interesante que Riva Palacio acepte el debate en los términos del filósofo inglés, es decir como un problema científico y, concretamente, sociológico, pero sus conclusiones son radicalmente distintas. Las ideas de Spencer son inaceptables para don Vicente porque anulan la libertad humana, ${ }^{2}$ pero también le repugna que despoje a la historia del mensaje moral que las biografias de los grandes hombres transmiten a la posteridad, y que anule el efecto de emulación que don Vicente supone se produce en el lector cuando conoce las vidas de hombres virtuosos. Riva Palacio no era precisamente un moralista: "Yo a la moral defino como ciencia -dice en una de sus poesías-de preparar ovejas a los lobos." Pero sin duda era un representante distinguido de la literatura romántica que mantenía el ideal de deleitar e instruir a un tiempo al lector, precepto antiguo que compartía con la mayor parte de la literatura occidental desde los tiempos de Homero.

${ }^{2}$ Quizá en este punto la lectura que hace Riva Palacio de Spencer es un poco forzada. Según Abelardo Villegas, para el filosofo inglés "el progreso de las civilizaciones a parece como una ley natural ineluctable, pero no como una ley que convierta a todos los individuos en autómatas subordinados a la necesidad, sino que opera a través de la libertad convirtiendo a esta misma en una necesidad". Abelardo Villegas, Positivismo y porfirismo, Secretaría de Educación Pública, México, 1972, pp. 11-12 (Sepsetentas, 41). 
Para la generación política y literaria a la que pertenece Riva Palacio, quien en aquel año de 1882 cumpliría 50 años, la irrupción -para esta fecha arrolladoradel positivismo, significó su desplazamiento de la vanguardia política e intelectual al asiento trasero de la diplomacia y las academias; pero como siempre sucede, lo más doloroso de contemplar era el espectáculo de un modo de pensar y de sentir que devenía en histórico. Esta amargura se delata en el prólogo que hizo don Vicente a Carmen, la novela de Pedro Castera publicada en ese mismo año:

El día en que los poetas no canten más que los combates o los triunfos del saber, el día en que los literatos sólo se ocupen de la ciencia o de la política, ese día que afortunadamente no ha de llegar, la sociedad se convertirá en un taller, en una academia, en una cátedra, en un cuartel o en un claustro; pero los destinos de la humanidad serán entonces más tristes que una tarde nublada. Felizmente no hemos llegadoa ese punto: todavía brilla el astro del sentimentalismo $[\ldots]^{3}$

La teoría del grande hombre que Riva Palacio defiende en este ensayo no sólo tiene un valor documental. En nuestros días la biografía sigue siendo el género predilecto de los lectores de historia y su utilidad científica es manifiesta ya sea a la manera nueva de François Xavier Guerra, o al estilo clásico de Enrique Krauze. Los avances de la historia económica y social no permiten ya entender la teoría del grande hombre del mismo modo que en el siglo XIX. Pero el problema teórico en torno al papel del individuo en la historia aún está lejos de hallar solución, si es que esto es posible. Además, la

${ }^{3}$ Pedro Castera, Carmen. Memorias de un corazón, Editora Nacional, México, 1958, p. IX. teoría del grande hombre tiene su manera de entenderse, como lo señala Jorge Luis Borges cuando compara dos de las obras fundadoras de la teoría, Los béroes y Los bombres representativos:

En efecto, los héroes, para Carlyle, son intratables semidioses que rigen, no sin franqueza militar y malas palabras, a una humanidad subalterna; Emerson los venera, en cambio, como ejemplos espléndidos de las posibilidades que hay en todo hombre [...] Emerson y Carlyle casi no tienen otro rasgo común que su animadversión al siglo XVIII. Carlyle fue un ecritor romántico, de vicios y virtudes plebeyas; Emerson, un caballero y un clásico. ${ }^{4}$

No será difícil ubicar a Riva Palacio en el sitio que le corresponde.

Álvaro Matute Aguirre, en otra sección de este número de Secuencia, hace un análisis brillante de un problema que hacía mucha falta resolver. Nos referimos a la manera imprecisa y equívoca con la que se utiliza en historiografía el término "positivismo" que, sin rigor alguno, se aplica ya a los seguidores de Herbert Spencer y Augusto Comte en México, ya a cualquiera que muestre alguna inclinación por los aspectos heurísticos de la investigación histórica. También analiza el caso de Vicente Riva Palacio quien a menudo es calificado, indebidamente, como perteneciente a la escuela positivista. El texto de Riva Palacio que presentamos a continuación ratifica lo dicho por Álvaro Matute: el responsable del México a través de los siglos era un escritor que estaba al día (y le gustaba demostrarlo), que combatió al positivismo sin dogmatismos extremos, conce-

\footnotetext{
4Thomas Carlyle, Los béroesy Ralph W. Emerson, Los bombres represenatativos, trad. y pról. de Jorge Luis Borges, W. M. Jackson, Nueva York, 1973, pp. XIII-XIV.
}

1 
diendo razón a veces, adoptando la terminología en boga, pero manteniéndose fiel al liberalismo político tradicional y al romanticismo literario que destila en todas sus obras. Riva Palacio -que se preciaba de haber nacido en la era de la industrialización-tenía una clara inclinación científica que lo condujo a adoptar un evolucionismo tomado de la cepa darwinista original, el cual plasmó de una manera interesante en su historia de la Nueva España. No hay duda pues, que Riva Palacio hizo suyas algunas ideas que se hallan también en el positivismo $y$, en particular, el concepto de evolución. Pero no por ello se le puede considerar positivista pues aun cuando es evidente que bebió de estas aguas llegó a conclusiones enteramente opuestas. Un ejemplo de ello es su estudio sobre las razas nativas de México (pp. 471-481 del tomo II de México a través de los siglos), en el cual aplica la teoría de la evolución de Charles Darwin y en particular la idea de que el hombre en su evolución fue perdiendo ciertos "apéndices cutáneos" (fundamentalmente el pelo) en la mayor parte del cuerpo; de ahí deduce don Vicente-después de un detenido estudio de antropología física del cual hay abundante documentación en su archivo personal-que los indios de México, lampiños como son, deben considerarse la raza con mayor grado de evolución. Compárese este planteamiento nacionalista con las ideas raciales de Francisco G. de Cosmes o con las de Francisco Bulnes y se apreciará la distancia que separa a Riva Palacio del positivismo convencional. A don Vicente se le puede calificar como un romántico que leyó a Darwin y lo adoptó a su modo, pero jamás fue alumno matriculado en la escuela de los señores Spencer y Comte.

\section{Francisco Sosa}

\section{Vicente Riva Palacio}

Aquí, en donde todos somos capaces de todo, dedicarse a la crítica literaria es empeño más peligroso que el de abrir un templo protestante en Puebla, o proponer en la Cámara la disolubilidad del matrimonio. Decir a un escritor que no sabe gramática, prueba más grande atrevimiento que el de Lutero al presentarse en la Dieta de Worms; y para demostrar a un poeta que su inspiración es postiza y de mala ley, se requiere más valor que el de Horacio Cocles, resistiendo solo en un puente a todo el ejército enemigo, que el de Marcelo atacando con un puñado de caballeros a la muchedumbre de los galos, según cuenta Valerio Máximo, o que el de Pedro Castera poniendo en venta sus Ensueñosyarmonias. No se puede ser crítico en un país en que cada literato se cree digno, no sólo de respeto, sino de la admiración de todas las generaciones presentes y venideras.

Todos los tormentos que se agotaron en Lyon en el siglo II de la Iglesia para martirizar a Blandina y a Póntico, parecerían poco castigo si se tratara de aplicárselos a un desgraciado que quisiera tomar el papel de censor en esta ciudad en que las letras están en su apogeo. Por eso, aunque me voy con tanto cuidado en mis artículos, como esos acróbatas que dan en los pueblos el 
espectáculo de cruzar con los ojos vendados sobre un terreno erizado de cuchillos y bayonetas, no dejo de maldecir en mi interior, el día y hora en que, por mi desgracia, me he metido en este laberinto, sin llevar, como el semidiós de la Grecia, el hilo maravilloso de Ariadna.

Pero a lo hecho, pecho; y vamos andando, que fin ha de tener todo esto y el hombre ha nacido para sufrir y padecer.

$Y$ hanme ocurrido todas estas reflexiones, porque voy a hablar de Pancho Sosa, que ha tenido siempre la franqueza de expresar sus verdaderas opiniones, todas cuantas veces ha escrito artículos de crítica literaria, lo cual le ha valido no pocos disgustos ni escaso número de malas voluntades.

Sosa, como crítico, algunas veces es demasiado severo; pero esto que más bien es resultado de su carácter, no ha dejado de ser útil en el tan desacotado campo de nuestra literatura; y como la venganza no sea arma extraña entre nosotros, muchos descargan sobre él sus rencores, sin perdonarle por más que pasen los días y los años; que entre los poetas, las ofensas, supuestas o reales, prescriben con más dificultad que en los siglos pasados los bienes raíces de la Iglesia o de los municipios.

Sosa ha engalanado, con sentidos versos y con leyendas, periódicos de buen nombre como El Domingo, El Federalista, El Renacimiento, El Artista y la Revista Mexicana.

A pesar de esto, será muy difícil que muchos confiesen el mérito de Sosa; y él se tiene la culpa, por andar queriendo decir siempre la verdad, en todas ocasiones, y por no darle tornillo a su carácter, poniendo en juego algo más que la indulgencia para llamar genios, a todos los que escriben cuatro renglones desiguales; eminencias, a los valles; cóndores, a los gorriones, y soles, a las anémicas linternas de los coches del sitio.

Para tener fama literaria bien sentada, es preciso callar todo lo que puede refluir en mengua de cuantos, bien o mal, escriban en todos los periódicos, libros y décimas de la plaza, conocidos y por conocer, y alabar hasta lo inalabable, por más que haya loas que parezcan inverosímiles.

Eso depende de los anteojos con que se lee.

Dijo un poeta:

\author{
En este mundo traidor, \\ Nada hay verdad ni mentira; \\ Todo es según el color \\ Del cristal con que se mira.
}

Cuentan que un carpintero tenía un caballo y sólo le faltaba la pastura para mantenerlo. Por las mañanas le echaba el aserrín y los recortes de madera, como almuerzo; pero como el animal nada de esto quería comer, al buen carpintero se le ocurrió, para que el caballo creyese que toda aquella madera era yerba húmeda y fresca, ponerle anteojos verdes. 
Necesítanse pues, unos lentes verdes, que así creeremos que todo es yerba, aun cuando mucho sea paja, y luego convencerse de que en materia de alabanzas todo debe regirse por el Do ut des, y facio ut facias.

Sosa ha tenido el candor de decir que las comedias de Cuenca, de Peza, de Segura, algunas de Chavero, otras de Juan Mateos y otras de Peón, no valen lo que los autores creen, o lo en que los cómicos las aprecian; y ha tenido con esto mucho que rascar.

Le han gritado envidioso, acre, intratable y antipatriota, porque el patriotismo tiene su modo de entenderse, aunque se haga alianza con el enemigo extranjero en un campo de batalla, con tal de que se diga siempre, que nosotros somos la raza privilegiada de la tierra para escribir en prosa y verso, ya hay seguridad de aparecer más patriotas que Mucio Escévola, que Vercingétorix, que Pelayo, o que Guerrero.

Es peligroso saber, y más que saber, publicar todos esos secretos misteriosos de la literatura, que se han vuelto ya como los secretos de las religiones. Cuentan que Aristófanes por haber hecho alusión a algunos misterios religiosos, fue acusado de impío, y no pudo salvarse sino probando que no estaba iniciado, y que todo aquello lo había sabido por la voz pública.

Renán refiere lo siguiente:

Un personaje elevado del islamismo me contó que había sido preciso hacía pocos años reparar el interior del sepulcro de Mahoma en Medina; y se publicó una convocatoria a los albañiles anunciando en ella que: aquel que tuviera que entrar a lugar tan sagrado, sería degollado al salir. No faltó uno que se presentara; descendió, terminó su trabajo y se dejó decapitar. Es necesario, me dijo mi interlocutor, que se tenga cierta idea de estos lugares y que nadie pueda decir que son de otro modo.

Esto es precisamente lo que causa la mala voluntad contra los críticos: es preciso que se tenga cierta idea de tales personas, y no sería malo degollar a todos los que intentaran probar que esa idea no es la verdadera.

Pancho Sosa se ha dedicado, principalmente, al estudio y publicación de biografías de los hombres que en México han tenido alguna importancia en las ciencias o en la literatura, o de alguna manera han contribuido al progreso moral y material del país, y tiene escritas ya más de 700 .

Este trabajo es ingrato y peligroso; pero entre los auxiliares de la historia, es sin duda el que mayores servicios le presta.

En las biografías de los hombres de pasados tiempos, la dificultad para encontrar datos fehacientes burla muchas veces el laborioso empeño del escritor, y las encontradas apreciaciones sobre el mérito de los contemporáneos le expone a los enconosos tiros de la envidia.

Con una serenidad imperturbable y con una constancia digna de respeto, 
Sosa arrostra por todo, y sigue sin interrupción estudiando y escribiendo biografías, y acumulando con ellas un caudal de noticias y juicios críticos que serán un tesoro para los historiadores en lo porvenir, por más que hoy no le produzcan a su autor ni grande honra ni provecho alguno:

La historia de los hechos de los hombres, que de alguna manera se distinguen por sus virtudes o por su saber, en los pocos años que viven sobre la tierra, se ha considerado siempre, si no de gran brillo, sí de notable utilidad, por escritores dignos de respeto.

"Antigua costumbre -dice Tácito en la vida de Agrícola- ha sido narrar los hechos y costumbres de los va-
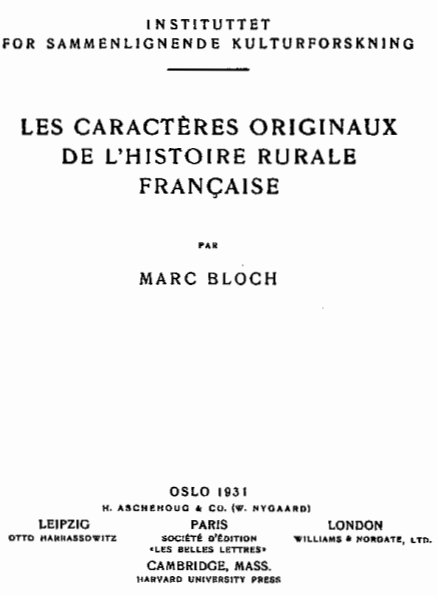
rones esclarecidos, y aun nuestra misma edad, aunque poco apreciadora de los suyos, siempre cuida de eso cuando alguna grande e ilustre virtud vence y sobrepuja la ignorancia, la envidia y el aborrecimiento de lo bueno, vicios comunes a las grandes ciudades y a las pequeñas poblaciones. Pero entre los pasados, así como había más inclinación a hacer cosas dignas de recuerdo y ocasión más oportuna para ello, así también movíanse los ingenios a escribir la memoria de esas virtudes, más por el precio de la buena conciencia que por el estipendio o la ambición. Narraron muchos sus propias vidas, confiando en la severidad de sus costumbres, que no aconsejados por la arrogancia; y por esto ni fueron murmurados Rutilo y Escauro, ni se dudó de la verdad de su dicho. Tanto así, en los siglos fecundos de virtudes, es fácil la justicia en la apreciación; y yo, escribiendo la vida de un hombre que ya no existe, necesito una indulgencia, que no solicitaría si atravesáramos los tiempos crueles y enemigos de las virtudes.

"Sabemos que Aruleno Rústico y Herenio Seneción fueron condenados a muerte por haber escritola apología, el uno, de Poetus Tráceas, y el otrode Prisco Helvidio; y no contentándose la persecución con los autores, fueron quemadas por la mano de un ejecutor, y en medio del foro, aquellas obras, esclarecidos monumentos del genio. Se pretendía, sin duda, consumir con el fuego la voz del pueblo romano, la libertad del Senado y la conciencia universal, ahogando la sabiduría de los profesores, y desterrando a todas las buenas artes por temor de 


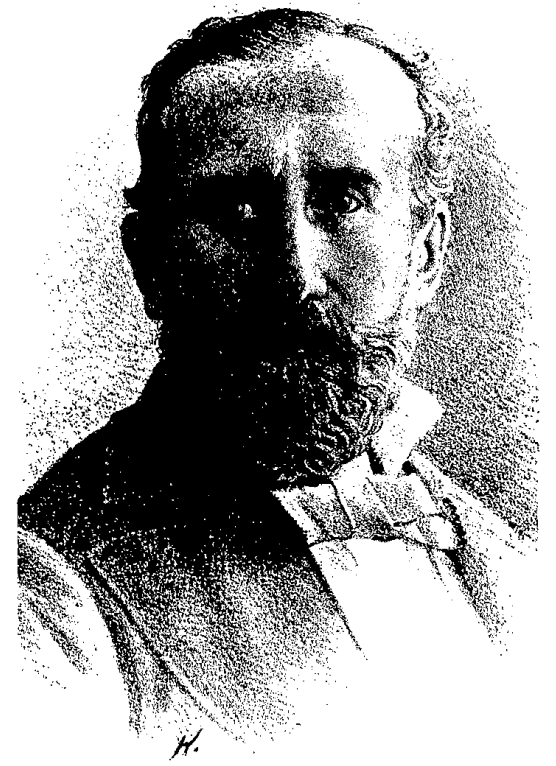

encontrarse con algo honesto. Ciertamente dimos grandes muestras de paciencia, y como la edad pasada vio los últimos términos de la libertad, vimos nosotroslos últimos dela servidumbre, perdiendo por temor a las denuncias hasta el trato y conversaciones familiares; y hubiéramos perdido hasta la memoria misma, si estuviera en nuestra potestad el olvidar como lo está el callar."

Después del testimonio del príncipe de los historiadores, que traducido por mí pierde toda la elegancia del original, nada sería preciso agregar en pro de los trabajos biográficos; pero de alguna cosa servirá aducir algunos otros.

Por tanto -dice Plutarco en la vida de Pericles- es visto que no son de provecho para los espectadores aquellas cosas que noengendran celo de imitación, ni tienen por retribución el incitar el deseo y conato de aspirar a la semejanza; mas la virtud es tal en sus obras, que con admirarlas, va unido al punto el deseo de imitar a los que las ejecutan, porque en las cosas de la fortuna, lo que nos complace es la posesión y el disfrute, pero en las de la virtud, la ejecución; y aquéllas queremos más que nos vengan de nosotros, y éstas por el contrario, que las reciban los otros de nuestras manos; y es que el honesto mueve prácticamente y produce al punto un conato práctico y moral, infundiendo un propósito saludable en el espectador, no precisamente por la imitación, sino por la sola relación de los hechos. De aquí nació para mí el propósito de ocuparme en este género de escritura.

El famoso escritor Manuel José Quintana, en el prólogo de sus Vidas de españoles célebres, dice al mismo propósito:

Las vidas de los hombres célebres son, de todos los géneros de historia, el más agradable de leerse. La curiosidad excitada por el ruido que aquellos personajes han hecho, quiere ver más de cerca y contemplar más despacio a los que con sus talentos, virtudes o vicios extraordinarios, han contribuido a la formación, progresos y atrasos de las naciones. Las particularidades y pormenores en que a veces es preciso entrar para pintar fielmente los caracteres y las costumbres, llaman tanto más la atención, cuanto que en ellas se mira a los héroes más desnudos del aparato teatral con que se presentan en la escena del mundo, y 
convertirse en hombres semejantes a los otros por sus flaquezas y sus errores, como para consolarnos de su superioridad.

Pero todos estos pensamientos se condensan de una manera admirable, en unos versos tomados de los que Antonio Pons pone en su Viaje a España y dice haberlos leído en dos tablas al lado del sepulcro del célebre conde Pedro Ansúrez, en una capilla de la catedral de Valladolid:

La vida de los pasados

Reprehende a los presentes;

Ya tales somos tornados,

Que mentar los enterrados

Es ultraje a los vivientes.

Porque la fama del bueno

Lastima por donde vuela,

Al bueno con la espuela,

$\mathrm{Y}$ al perverso con el freno.

Jenofonte lleva más adelante el empeño en conservar el recuerdo de las acciones de los hombres ilustres, pues dice al comenzar El banquete. "Me parece que no solamente las acciones serias de los hombres honrados y virtuosos, sino aun sus simples entretenimientos, son dignos de memoria; y llevado de este pensamiento, quiero publicar algunos rasgos de que yo he sido testigo."

Seguramente por esto hay tantos escritores honrados que se han dedicado a los estudios biográficos. Tácito escribió la vida de Agripa, Quinto Curcio la de Alejandro Magno, Plutarco y Cornelio Nepote, vidas de griegos y romanos, Jenofonte la de Ciro el Grande, y Diógenes Laercio las de muchos filósofos; Suetonio las de los doce césares, Filóstrato la de Apolonio de Tiana y la de los sofistas, Eunapo las de los filósofos.

El año de 1643, el jesuita Bolland comenzó la publicación de la grande obra Acta sanctorum, interrumpida en 1794 por la revolución, y que no comprendiendo más que del 1 de enero al 14 de octubre, contaba ya 53 volúmenes en folio. Monge, en nombre del Instituto; Guizot, en nombre de la historia, y los personajes más importantes de Bélgica, pidieron la conclusión de ese monumento que, por un voto de las cámaras belgas en 1837, se continuó por una sociedad de bollandistas escogida de la Compañía de Jesús; hasta 1853 habían publicado ya dos grandes volúmenes con más de 2400 páginas.

Estas biografías de los santos, tan populares en el mundo católico, son el resumen de la literatura dominante de la edad media, que ejerció influencia tan poderosa en el modo de ser de las sociedades y en el modo de existir de los gobiernos.

En nuestros días, a la luz deslumbradora de la ciencia moderna, apenas 
puede comprenderse el influjo decisivo que esas leyendas tuvieron en el ánimo de aquellas generaciones, no sólo en la vida doméstica, no sólo en el criterio de la conciencia religiosa y moral, sino en la guerra, en las ciencias, en las artes, en las letras y en la industria.

Relatos de fantásticas y maravillosas aventuras, milagros, éxtasis, profecía, ubicuidad, penitencias espantosas y episodios de abnegación inverosímiles; los santos de la Iglesia de oriente venciendo en constancia y en sufrimientos a los faquires del Ganges y del Indo, los estilitas permaneciendo inmóviles sobre su columna tantos años y anidando bajo sus brazos los pájaros; María la Egipcia enterrándose viva hasta el cuello; los mártires de la Iglesia de occidente, sufriendo sin murmurar y muchas veces en medio de cantos triunfales, los horribles martirios de la silla candente y la muerte entre las garras de los tigres o las pesadas patas de los elefantes; la innumerable muchedumbre de solitarios, haciendo una monstruosa mezcla de la filosofía de los gimnosofistas, de los pitagóricos, de los estoicos y de los cristianos; este es el almacén de donde están sacados todos los hilos, que tejen y traman la vida de los santos, durante los tres primeros siglos de la Iglesia.

Y sin embargo, estas vidas, llevadas por la tradición, inspiraron a toda la edad media, y puede decirse que de ellas nacieron los libros de caballería; los libros de caballería que no son otra cosa sino biografías más o menos fantásticas de hombres maravillosos; porque la humanidad, por más que digan los escritores católicos, tiende al politeísmo, y los santos son para el vulgo del catolicismo una especie de semidioses, como lo fue Teseo entre los griegos, como lo fue Hércules antes de ser elevado a la categoria de dios, y semidioses fueron para la edad media, los caballeros andantes; porque el pueblo en los días del politeísmo criaba sus semidioses; en los primeros siglos del cristianismo, formaba santos milagrosos; y cuando la Iglesia estableció que los santos no se declaraban más que en Roma, el pueblo comenzó a crear demonios y héroes fantásticos y legendarios.

Libros de caballería y vidas de los santos, fueron el alimento literario de san Ignacio de Loyola, que envolvió al mundo en una red de acero con la Compañía de Jesús; vidas de los santos y libros de caballería, nutrieron el espíritu de la sublime histérica Teresa de Jesús, y quizá el Fausto de Goethe y el Mágico prodigioso de Calderón hayan tenido, como opinan muchos, la vida de san Cipriano por fuente de inspiración.

En los últimos siglos, las colecciones biográficas han tomado generalmente el carácter de diccionario, y se han formado grandes colecciones. Branthome, Moreri Lndvocat, Bayle, Michaud, Vaperau, Renniè y otros muchos cuya lista sería interminable, se han dedicado a esta clase de trabajos, entre los cuales no son de despreciarse el de Robertson en la Vida de Carlos $V$, Watson en la de Felipe II, y el mismo Voltaire en la de Carlos XII.

Hay sin embargo, en medio de todo esto, la biografía que podríamos 
llamar bastarda: la que escriben los aduladores para halagar el amor propio y lisonjear servilmente a un magnate, profanando el recuerdo de Plutarco y convirtiendo las balanzas de la justicia en romana de tienda de abarrotes en que se pesa para vender.

Esta clase de biografías son como la flor que llamamos nosotros de Navidad; son como la maravilla: apenas pueden vivir siquiera durante el día que las ve nacer; pero de este trabajo debe hacerse el mismo aprecio que el público hace de él: le considera como uno de tantos medios que han inventado los cortesanos para halagar a su señor; se leen por diversión como la noticia de la sierpe que se apareció en la iglesia de Loreto, y si sirven para hacer alguna calificación, no es precisamente la del personaje de quien se habla, sino la del Homero que a tal Aquiles canta. De tales obras nunca hemos llegado a ver una colección, y a fe que hace falta, no como un modelo de literatura ni menos como dato histórico, sino como prueba de la volubilidad de las cosas de este mundo, y como coeficiente de abyección en algunos periodos de la vida de los pueblos.

Cuando se medita en la influencia de los estudios biográficos, viene necesariamente a nuestra memoria la gran cuestión a que se ha llamado la teoria del grande hombre, y sobre la que voy a permitirme decir unas cuantas palabras, siquiera para poder hablar de grandes hombres, ya que entre nosotros son tan escasos.

Otra clase de espíritus hay -dice Spencer en su obra Introducción a la ciencia social que no está mejor preparada para interpretar científicamente los fenómenos sociales: aquella que no considera en el curso de la civilización, sino un recuerdo de los personajes notables y de sus acciones. Uno de los que han expuesto esta teoría con más brillo ha dicho esto: "Yo concibo la historia universal, como la historia de lo que el hombre ha hecho en el mundo, y esto en el fondo forma la historia de los grandes hombres que en él han existido." En esta creencia, aunque no tan netamente formulada, hemos sido educados casi todos nosotros.

Se extiende después Spencer explicando por qué a su juicio la teoría del grande hombre ha sido tan bien

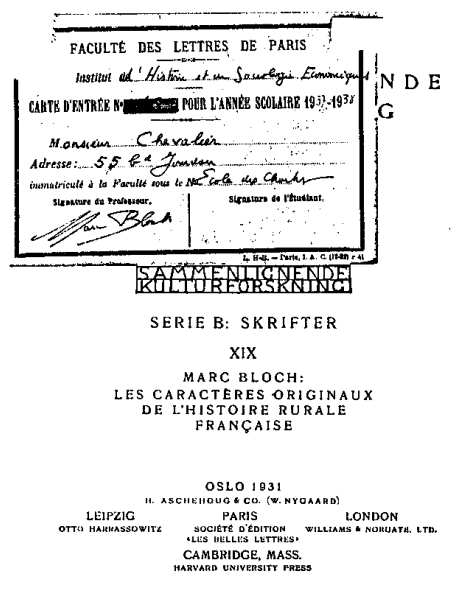


recibida, y por qué encuentra tan fácilmente espíritus preocupados para aceptarla, y que buscan siempre el influjo de una personalidad eminente en todos los progresos humanos y en todas las evoluciones sociales.

El gusto universal por la personalidad, cualidad activa y persistente en todos los hombres, el interés y el entretenimiento que lleva consigo el relato de acciones y palabras de grandes hombres, y la facilidad con que los hechos históricos y los problemas sociológicos de pasados tiempos se explican por la intervención y poderoso influjo de un hombre distinguido, son, a juicio del eminente filósofo a quien me refiero, las causas que más eficazmente contribuyen a mantener en el mundo de la inteligencia la teoría del grande hombre, y a dificultar el estudio de las ciencias sociales.

"Pero si descontentos de la vaguedad-dice Spencer- buscamos que nuestras ideas sean más exactas y precisas, descubrimos que esta hipótesis es profundamente incoherente. Si en vez de darnos por satisfechos explicando así el progreso social, queremos profundizar más y preguntarnos ¿de dónde viene el grande hombre? encontramos la teoría completamente defectuosa; porque hay dos soluciones posibles para esta cuestión: o el origen del grande hombre es sobrenatural, o es natural. En el primer caso es un dios en misión, y caemos en el principio teocrático, $\mathrm{O}$ más bien dicho, no caeremos, porque estamos obligados a conceder a

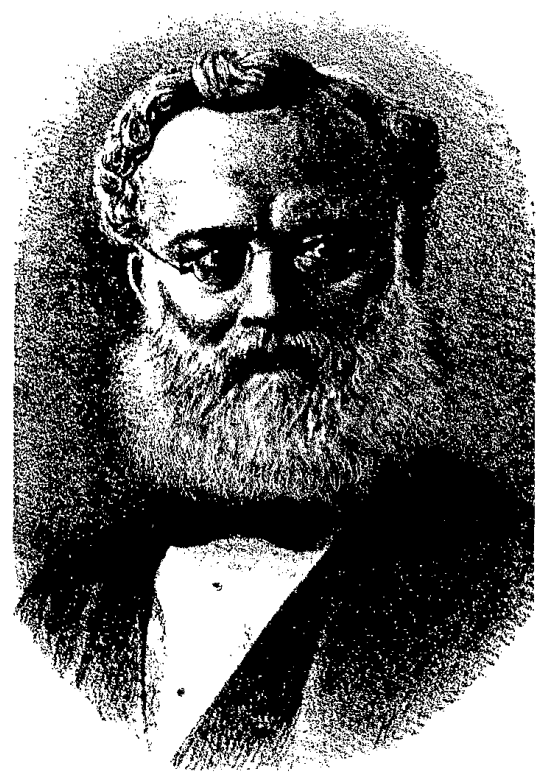
M. Schomberg, citado más arriba, que la determinación de invadir a la Bretaña fue inspirada a César por la divinidad, y que desde él hasta Jorge III el Grande y el Bueno, nuestros amos fueron escogidos sucesivamente para cumplir los designios sucesivos de Dios. ¿Puede ser aceptable esta solución?

"Por otra parte, si el grande hombre tiene un origen natural, preciso es clasificarle sin vacilar entre los otros fenómenos de la sociedad donde ha nacido, y entre los productos de los estados anteriores de esa sociedad. En el mismo grado que toda la generación de que forma una pequeña parte; en el mismo que las instituciones, el lenguaje, la ciencia y las costumbres; en el mismo que la multitud de las artes y sus aplicaciones, el 
grande hombre no es más que una resultante del enorme agregado de fuerzas, que han obrado de concierto durante muchos siglos.

"Tendréis a la verdad el derecho, si os place, de ignorar lo que enseña la observación más vulgar, y que confirma la fisiología, si admitís que de padres europeos pueda nacer un niño negro, o que dos papus de cabellera crespa sean capaces de producir un hermoso niño del tipo caucásico y de cabellos lacios. Tendréis también que admitir bajo ese supuesto, que el grande hombre puede aparecer no importa dónde ni con qué condiciones. Si no queréis tomar en cuenta estas resultantes, acumuladas por la experiencia y expresadas hasta en los proverbios vulgares lo mismo que en las generalizaciones de los psicólogos, si suponéis que Newton pueda nacer de una familia de hotentotes, y un Milton pueda surgir en medio de los andamanes, que un Howard o un Clarckson pueda tener a los fidjienes por padres, entonces podréis fácilmente explicar el progreso social, como producido por la acción del grande hombre.

"Pero si toda la ciencia biológica, viniendo en apoyo de las creencias populares, acaba por convenceros de que es imposible que un Aristóteles venga de un padre y una madre cuyo ángulo facial mida 50 grados, y que no hay la menor probabilidad de que aparezca un Beethoven en una tribu de caníbales, cuyos coros en un festín de carne humana semejan un gruñido rítmico, estaréis obligados a admitir que la génesis del grande hombre, depende de largas series de influencias complejas, que han producido la raza en medio de la cual aparece, y el estado social al que ha llegado lentamente esa raza.

"Si es verdad que el grande hombre puede modificar de su nación la estructura y las acciones, también es cierto que antes de su aparición ha habido forzosamente modificaciones que han constituido el progreso nacional; antes que él pueda reformar la sociedad, es necesario que la sociedad le haya formado a él; todos los cambios de que es autor inmediato tienen causas principales en las generaciones de que él desciende; si existe una explicación verdadera de tales cambios, preciso es buscarla en el conjunto de condiciones de donde han salido los cambios y el hombre."

Más especioso que verdadero viene a ser todo este razonamiento de Spencer. Lo que todos han creído, y que forma la base de la teoría del grande hombre, es que hay en la historia personajes que han influido directamente en el progreso o retroceso de la nación a que pertenecen, o de gran parte de la humanidad; que muchas evoluciones sociales pueden explicarse por el influjo de un hombre, y que la historia de muchos de estos grandes hombres, es la historia de su país o de su época; así parece que Spencer comprende 'también la teoría del grande hombre, y bajo este sentido es como la ataca y llama preocupados a los que en ella creen.

Indudablemente, ni todo el progreso, ni todas las evoluciones sociales 
pueden tener explicación satisfactoria en la teoría del grande hombre; pero es una preocupación sistemática negar su influencia y establecer como principio absoluto que el grande hombre no es sino el resultado, y nunca causa única, o cuando menos cooperativa, del progreso.

No necesitamos ocuparnos de si el nacimiento del grande hombre es natural o maravilloso, supuesto que no admitimos entre los datos para la resolución de los problemas científicos nada que no sea enteramente natural; pero a nuestro turno ponemos también este dilema: o la evolución social tiene que verificarse precisa e indispensablemente, indefectible en tiempo y en modo, o está sujeta a la eventualidad de todos los acontecimientos sociales y es susceptible de variar en tiempo y forma, y de ser o no ser. Si lo primero, entonces tendremos ya el fatalismo árabe, el estaba escrito, y por consecuencia el destino manifiesto, la falta de libertad naciendo del conjunto de las libertades; el libre albedrío de las unidades engendrando una unidad arrastrada ciegamente por el destino, como los personajes de Esquilo; las afirmaciones coordinadas produciendo la negación absoluta; en fin, la deidad ciega de la mitología, el Alá del islamismo; lo maravilloso también, y sobre todo más que lo metafísico, lo teológico: un Jehová disponiendo caprichosamente de la suerte de las sociedades. Esto no se puede admitir. Entonces, busquemos el otro extremo de la disyuntiva, y establezcamos sin vacilar que las evoluciones sociales no son absolutamente necesarias, ni en su tiempo ni en su modo de ser, y que están sujetas a la combinación de los elementos que hacen de ellas la unidad más compleja y menos resoluta para el estudio científico.

Para combatir la argumentación de Spencer, me valdré de principios y de reflexiones tomadas del mismo autor; pero con el objeto de ni presentar como mío lo que no es, ni tener a cada paso que estar advirtiendo de quién he tomado esas palabras, pondré subrayadas todas las frases que traslado del sabio filósofo y que recojo de varias de sus obras.

Una sociedad, cualquiera que sea, no puede compararse, por más que sea un agregado, ni con los agregados inorgánicos, ni con los orgánicos; no con los primeros, porque un todo cuyas partes son.vivientes, no puede tener caracteres generales semejantes a los de aquel cuyas partes están privadas de vida; no con los segundos, porque las partes de un animal forman un todo concreto, mientras las de una sociedad forman un todo discreto; las unidades vivas que pueden componer al animal, están unidas en estrecho contacto, en tanto que las que componen a la sociedad, son libres, discretas y dispersas más o menos lejos unas de las otras.

Pero la ciencia sociológica considera las unidades sociales, sometidas a ciertas condiciones constituidas física, emocional e intelectualmente, en posesión de ciertas ideas adquiridas y de sentimientos correspondientes, y tiene por misión explicar los fenómenos que resultan de estas acciones combinadas. 
Es claro que la sociedad influye sobre el individuo, comoel individuo en la sociedad, y es necesario estudiar ambas influencias, porque esta es una de las primeras incógnitas que debe eliminarse en el problema.

En una evolución social, pueden considerarse muchas causas productoras, impulsivas, reguladoras, persistentes o variables; pero como no nos vamos a ocupar más que de la influencia del hombre, o más bien dicho, del grande hombre, en esas evoluciones en que a él le creemos el principal factor, no trataremos de ninguna de esas otras fuerzas motrices.

En una sociedad, las diversas unidades vivientes están en contacto las unas con las otras, y son diferentes por la intensidad de sensación y emoción que causas semejantes pueden pro-

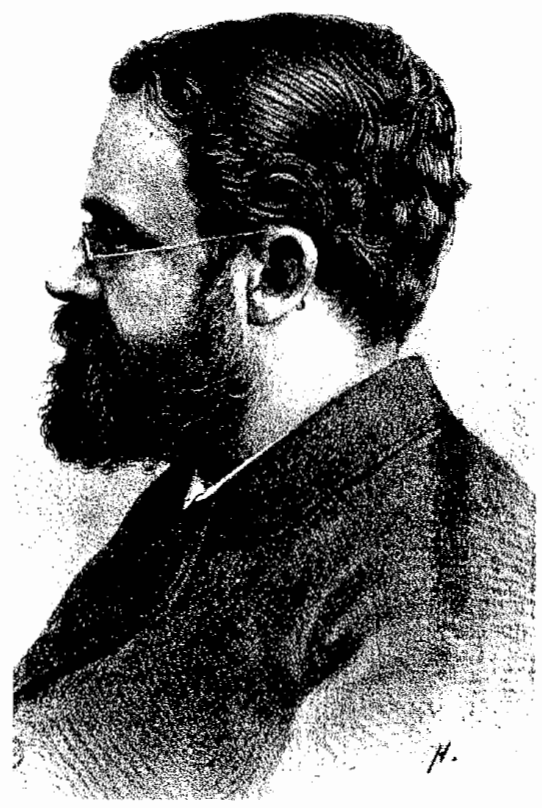
ducir en ellas; mientras unas se muestran insensiblés, otras poseen en alto grado la sensibilidad; en una misma sociedad, entre miembros que pertenecen a la misma raza, y más aún, siendo razas distintas, se encuentran estas diferencias: las unidades entregadas a un trabajo mecánico y a una vida penosa, son menos sensibles que las que viven la vida mental.

De aquíse puede inferir con seguridad, que hay una parte social que debe influir decididamente sobre la otra, o al menos que está en aptitud de dirigir el movimiento y evolución; pero aún hay más: ciertas clases sociales influyen decisivamente en la marcha de la evolución, precipitándola o deteniéndola, como por ejemplo: un grupo de ciudadanos que produce algún artículo para el consumo nacional, o que provee de alguna manera las necesidades sociales; este grupo en diferentes tipos, aparece en cada localidad, según su industria o comercio, apoderándose de todos los destinos de aquella localidad; dominando y dirigiendo la evolución en el sentido más conveniente a su clase, ya minera, ya agrícola, ya manufacturera, ya comercial.

Y. más notable se hace la preponderancia de una de estas clases, cuando en un país agrícola por ejemplo, viene a descubrirse una gran riqueza mineral; entonces la influencia dominante en la evolución que allí se verifica desde 
aquel momento, está en el grupo que impulsa la industria que acaba de descubrirse; en virtud del movimiento progresivo, se adueña completamente de aquella situación. Este es un extracto de Spencer.

Pues no sólo ese grupo puede imprimir una marcha determinada a la evolución, sino precipitarla fuera de tiempo y orden:

lo mismo que en el embrión de un animal superior se ven partes importantes de diversos órganos aparecer fuera del orden primitivo por anticipación, lo mismo para el cuerpo en general sucede que órganos enteros que en la serie de fenómenos de la génesis primitiva del tipo, han aparecido relativamente tarde, se manifiesten relativamente violentos en la evolución del individuo; esta anticipación que el profesor Haeckel ha llamado beterocronia, se manifiesta por la aparición rápida del cerebro, en el embrión del mamífero [...] Cambio análogo de orden de evolución social, se nos revela por la formación de sociedades nuevas que heredan habitudes o costumbres de sociedades antiguas.

Vemos, pues, dos cosas: que hay desarrollos que pueden llamarse prematuros, y que éstos son muchas veces producidos por agrupamientos que influyen sobre el cuerpo social.

Y ahora, ¿podrá negarse que estos agrupamientos agrícolas, industriales, etc., despiertan, se mueven, se organizan y se ponen en actividad por la iniciativa, el cálculo, la ciencia, la constancia o el atrevimiento de un hombre? ¿Será necesario poner ejemplos de esto en un siglo en que las sociedades anónimas, que nacen siempre de la idea de un solo hombre, están produciendo una inmensa evolución en todo el mundo civilizado? ¿Será necesario citar casos cuando apenas habrá individuo medianamente acomodado que no tenga parte o intervenga de alguna manera en alguna sociedad anónima, creada por la iniciativa de un solo hombre?

Pues lo que se dice de la influencia de éstos en lo relativo al movimiento de mejora material, no hay motivo para negarlo tratándose de una evolución religiosa, filosófica o política.

La gran objeción que se hace, es que todos los grandes hombres fueron a su vez influidos por la sociedad, y recibieron el acopio de conocimientos de las generaciones anteriores; que de una tribu de caníbales no puede surgir un Beethoven, de una madre que tenga un ángulo facial que mida menos de $50^{\circ}$, nacer un Aristóteles, ni un Newton de una familia de hotentotes.

Esto es llevar el razonamiento al ridículo, y hablar con los hombres que se dedican al estudio de la sociología, como si se dirigiera la palabra a un grupo de marmitones, o a una reunión de niños que estuvieran apenas comenzando la educación primaria.

Jamás los escritores que han creído en la teoría del grande hombre, han negado la influencia de la sociedad y de los conocimientos adquiridos por las generaciones anteriores en el hombre que, a su vez, la ejerce tan decisiva en 
sus contemporáneos y en sus pósteros, ni han supuesto nunca que un lipan o un apache convirtiéndose de pronto en un Humboldt o en un Laplace, pueda hacer repentinamente de su tribu un grupo tan ilustrado como los miembros del Instituto, y tan aristócrata como los señores del Faubourg Saint Germain en París, ni menos han creído que del centro del África ecuatorial aparezcan inesperadamente un Dante, un Wagner o un Víctor Hugo.

Las sociedades, como la naturaleza, no caminan a saltos; las evoluciones sucesivas se encadenan unas con las otras de una manera lógica; pero en las sociedades, la lógica de una evolución no exige ni que sea en tal sentido mejor que en tal otro, ni en tal tiempo con preferencia a tal otro. Después que han pasado se hace gala de sabiduría, explicando los motivos que la prepararon y desarrollaron; pero como se trata siempre de dar explicación a un hecho consumado, y el más ilustre es aquel que mejor lo explica, se tiene miedo de decir que pudo esto haber sido de otra manera tan fácilmente que como fue. Si el termómetro bajó repentinamente seis grados, es muy sencillo afirmar que una corriente fría que vino del norte determinó el brusco cambio en la temperatura, y nadie se toma el trabajo de sostener que pudo muy fácilmente haberse producido un fenómeno meteorológico que elevara a cuatro grados el calor.

La teoría del grande hombre no implica necesariamente la idea de que él ha creado los elementos sociales, sino que él los amalgama, los combina, los aprovecha y los dirige en tal sentido, que producen una evolución inesperada, o que violentan la que debía venir; y en cualquiera de estos dos casos, es la influencia de aquel hombre la que se siente en la evolución, y la historia de ella es la historia de él.

Si la evolución viniera ya formada, y el grande hombre fuera como ella, producto natural de la sociedad, ipor qué esas grandes luchas de los grandes iniciadores y de sus discípulos, contra las sociedades que les rodean? ¿Por qué esa crucifixión de Jesús y ese sangriento combate de tres siglos para establecer el cristianismo, si era una evolución que había verificado ya la sociedad? ¿Por qué esa persecución y ese aislamiento de Mahoma y esa hégira, y esas guerras tremendas, si ese mundo islámico había engendrado la revolución del profeta? ¿Por qué las grandes guerras de religión que siguieron a la Dieta de Worms, si Lutero no hacía más que responder a un hecho consumado? Y ¿por qué Galileo y Colón no encontraron todas las facilidades, el uno en su sistema y el otro en sus descubrimientos, si no eran ambos más que el eco de los conocimientos sociales de su siglo?

Las opiniones de Spencer, además de no ser fundadas, envuelven la más negra ingratitud de la humanidad para con los hombres que han aprovechado los elementos sociales precipitando la marcha del progreso; y si llegaran a establecerse como regla en las naciones, además de convertir a la sociedad en una especie de planta, sin libertad de iniciativa, que debía necesariamente 
florecer en la primavera, dar sus frutos en otoño y secarse en el invierno, siguiendo fatalmente una ley que no conoce, establecería la absoluta irresponsabilidad sociológica de todos los gobiernos; la más completa inutilidad en todas las instituciones, y el esterilismo más triste en los esfuerzos de los hombres públicos. La evolución ha de venir, ha de llegar y ha de pasar precisamente; si la influencia del grande hombre no debe de tomarse en cuenta, no hay motivo para que se tome tampoco la de hombres que apenas serán "medianos"; si no hay que agradecer a los que pasaron, no hay ni que temer ni que esperar de los que son; la sociología debe estudiarse entonces sólo como la biología de una nación, aunque Spencer diga que "la sociedad no es más que un nombre colectivo empleado para designar cierto número de individuos".

Mientras no se encuentren nuevas razones, creeré que el grande hombre influye directamente sobre su nación y sobre su época; porque aun creo más, que hay acontecimientos y pequeñas causas, que pueden producir, por un encadenamiento de circunstancias, grandes evoluciones, como el maquinista que en una locomotora no necesita más que abrir fácilmente unos cuantos grados el ángulo de una palanca, para despertar ese pavoroso movimiento de émbolos y ruedas que ponen en marcha un enorme tren cargado de mercancías; y pensaré con Renán, cuando dice: "Hay más de un ejemplo de cosas bellas y permanentes que no se han fundado sino sobre una niñería: es preciso no buscar ninguna proporción entre el incendio y la chispa que lo produce."

Así pues, para todos los hombres que deseen para sí y para sus sucesores, nobles modelos de virtud que imitar, dechados de constancia en el estudio que seguir, y una esperanza que alimentar de que su nombre y sus sacrificios no se olvidarán, el trabajo de los escritores de biografías debe tener una alta estima.

Ojalá Sosa, comprendiendo esto, recuerde siempre cuántas buenas voluntades están de su lado, y no desmaye en sus ávidas tareas, y siga sacando del olvido a tantos como lo merecen por sus virtudes o su ciencia, y desdeñe como pequeñas miserias de la vida, los tiros de los que hoy puedan atacarle. 